\title{
Prospective remembering: Perceptually driven or conceptually driven processes?
}

\author{
MARK A. MCDANIEL \\ University of New Mexico, Albuquerque, New Mexico \\ BRIDGET ROBINSON-RIEGLER \\ Augsburg College, Minneapolis, Minnesota \\ and \\ GILLES O. EINSTEIN \\ Furman University, Greenville, South Carolina
}

\begin{abstract}
Converging experimental operations and several prospective memory tasks were used across three experiments to determine the extent to which prospective remembering is supported by datadriven versus conceptually driven processes. In all experiments, subjects were asked to perform an action when a target item later occurred. When the semantic context changed from encoding to test, prospective memory significantly declined (Experiment 1). When the target event (the item, which in its subsequent appearance in the experiment was the signal to perform the action) was presented as a word (relative to picture presentation, Experiment 2) or was encoded nonsemantically (relative to semantic encoding, Experiment 3), there was a decline in prospective memory performance. Dividing attention during prospective memory retrieval substantially reduced prospective memory performance (Experiment 3). The results of this research indicated that prospective memory is largely conceptually driven, and it behaves more similarly to direct rather than indirect conceptual tests. We suggest that prospective remembering of the type studied here is mediated by a reflexive episodic associative memory system as proposed by Moscovitch (1994).
\end{abstract}

The processes that support remembering past events (i.e., retrospective memory) have been well studied in the experimental literature and extensively considered by theoreticians. In contrast, the way in which people remember to do things at some time after the intention is encoded has received relatively little attention (Brandimonte, Einstein, \& $\mathrm{McDaniel}, 1996$ ). (To be consistent with the literature, we will label this memory task prospective memory.) This is true despite the obvious importance of prospective remembering in the real world, wherein many everyday memory demands, such as remembering to pack a lunch, call a colleague, and take medication, are all prospective in nature.

Prospective memory holds interest from a theoretical perspective as well. To use Tulving's (1983) terminology,

This research was supported in part by National Institute on Aging Grant AG08436 and by a Purdue Research Foundation Grant. Experiments 1 and 2 were conducted in partial fulfillment of the requirements for B.R.-R.'s master's degree at Purdue University. The experiments herein were partially described in chapters in edited volumes (Einstein \& McDaniel, 1996; McDaniel, 1995). The authors thank James Kammer for assisting in the data collection of Experiment 3, and Melissa Guynn for help with data analysis. The authors also appreciate Mike Masson and an anonymous reviewer for their helpful comments on a previous version of the paper. Correspondence should be addressed to M. A. McDaniel, Department of Psychology, University of New Mexico, Albuquerque, NM 87131 (e-mail: mcdaniel@unm.edu).

-Accepted by previous editor, Geoffrey R. Loftus explicit retrospective memory tests direct a person to be in a retrieval mode (see also Craik, Govoni, Naveh-Benjamin, \& Anderson, 1996). Unlike for these retrospective memory tasks, however, for a prospective memory task, there is no external agent (e.g., an experimenter) that prompts the person to initiate memory retrieval (or, in Tulving's terms, to place the cognitive system into a retrieval mode). Accordingly, remembering to perform an action at a given circumstance (e.g., remembering to give a friend a message when you see her) appears to require more spontaneous memory retrieval than has been captured by theories of explicit retrospective memory (Einstein \& McDaniel, 1996). Interestingly, this distinction has deep historical roots. Ebbinghaus (1885/1964) identified several kinds of memories, with one kind of memory reflecting voluntary production of past experience (e.g., recall, recognition) and another kind reflecting the spontaneous appearance of a mental state, "without any act of the will" (p. 2). In spite of Ebbinghaus's longstanding distinction, the processes that support this latter kind of memory - in particular, in terms of prospective remembering - have not been extensively considered from either an experimental or a theoretical standpoint. The general objective of the present study was to begin to reveal the nature of the processes that support prospective remembering.

Our approach was to examine prospective memory from the perspective of a current framework used to characterize a range of memory tasks of interest in the con- 
temporary literature. This framework suggests that memory tasks differ in the degree to which they require datadriven, as opposed to conceptually driven, processes. Data-driven processes are those that depend on perceptual information, and many indirect retrospective memory tasks (e.g., word-completion tasks) have been found to rely on data-driven processes (Hamann \& Squire, 1996; Roediger, Weldon, Stadler, \& Riegler, 1992; Weldon, 1991). Conceptually driven processes are those that recruit meaning to support task performance, and most direct retrospective tests (e.g., recall) are widely considered to be conceptually driven (e.g., see Roediger, Weldon, \& Challis, 1989).

In the present three experiments, we used a set of converging experimental operations and several prospective memory paradigms to determine whether prospective memory is supported primarily by data-driven processes or by conceptually driven processes. In doing so, we hoped to provide benchmarks for considering prospective memory in relation to more well-investigated memory tasks and theoretical accounts of those tasks. We will develop these considerations and a theoretical account of prospective memory in the General Discussion after reporting the findings of the experiments.

One hypothesis is that prospective remembering is largely data driven. This hypothesis is based on the observations that (1) performance on many indirect memory tests is data driven and (2) prospective memory shares some formal features with indirect memory tests. Paralleling an indirect-memory task, a prospective memory task does not involve a direct instruction to interrogate episodic memory in order to formulate a response. Rather, the influence of previous episodic experiences is resurrected in a more spontaneous fashion. For example, one of the prospective memory tasks used herein requires subjects to press a key when a designated event appears on the computer screen. This prospective memory response is stimulated by the appearance of the event (a certain word) with no prompt to remember the previous encoding of that word during the experiment (the prospective memory study phase); similarly, on an indirect retrospective test, responding with a particular word (that appeared previously) is stimulated by the appearance, in some form, of that stimulus (fragmented or perceptually degraded word) with no prompt to remember the previous encoding of that word (the study phase). The idea here is that, in the absence of explicit directions to activate a memory search, perhaps the cognitive system relies on data-driven processing to initiate memory retrieval in a prospective memory task. For instance, perhaps the fluency of processing an environmental cue (that signals the appropriateness of performing the prospective memory action) initiates retrieval of prior encoded associations of that cue (cf. Einstein \& McDaniel, 1996; McDaniel, 1995), so that an intended action is spontaneously remembered. This analysis is consistent with McDaniel and Einstein's (1993) finding of a modest correlation between prospective memory performance and priming in word-fragment completion, an indirect memory task considered to be primarily data driven (Hamann \& Squire, 1996; Roediger et al., 1992; Weldon, 1991).

Alternatively, there are reasons for expecting that prospective memory relies more extensively on conceptually driven processes than on data-driven processes. Though there are few data on the issue, it would seem that prospective remembering often is accompanied by, or is mediated by, some awareness of the previously encoded intention and the context in which this intention was originally encoded. Such awareness of the episodic context in which the original encoding occurred is a salient dimension of direct retrospective tests (at least in contrast to indirect retrospective tests), and such awareness of episodic context has been linked to conceptual, elaborative processes (Masson \& MacLeod, 1992). Accordingly, conceptually based processes may be heavily involved in prospective remembering.

Before proceeding, it is worth noting that identifying data-driven processes in prospective remembering would not in and of itself link prospective memory to processes or systems underlying indirect memory tests, because certain direct retrospective tests may promote extensive datadriven processes (Blaxton, 1989; Roediger \& Blaxton, 1987; Weldon \& Roediger, 1987); nor would evidence for conceptually based processes in prospective remembering necessarily link prospective memory to processes or systems underlying direct retrospective memory tests, because indirect tests can be conceptually driven (Blaxton, 1989; Roediger \& Blaxton, 1987). Accordingly, as the nature of the processing involved in prospective remembering begins to be delineated by our initial experiments, further markers of the relation of prospective memory to direct versus indirect memory tests will be examined.

\section{EXPERIMENT 1}

Experiment 1 tested the effect of a manipulation on prospective memory that has been used as a marker of data-driven versus conceptually driven processing in retrospective memory tasks. Before describing the manipulation, it is necessary to first sketch our general prospective memory paradigm, based on that developed by Einstein and McDaniel (1990). Our paradigm busily engages subjects in a set of ongoing tasks and requires them to remember to perform some activity at some future point in the experiment (e.g., press the F10 key on a computer keyboard). In an instructional phase, we specify environmental events (usually one or several words) that should be responded to with the prescribed activity whenever that target event appears in a designated task (e.g., whenever bat is presented in a sentence verification task). We view this prospective memory task as somewhat analogous to giving "Patty" a message when you next see her. In order to discourage subjects from continuously holding the intended action in working memory, distractor activities are included between the prospective memory instruction and the time at which the action is to be performed. 
In Experiment 1, we manipulated the degree to which the semantic context at encoding of the prospective memory target event matched the context at test (i.e., when the prospective memory activity was supposed to be performed). The subjects were presented with a homographic word (bat) for which one meaning was instantiated by embedding the word within a sentence that biased one particular meaning at encoding. At retrieval, the word was presented in the context of the same meaning (same condition), a different meaning (different condition), or with the same meaning but embedded within a different situation (modulated condition; i.e., a bat hanging upside down at encoding and a bat flying at retrieval).

Varying the semantic context from encoding to test is a strategy that has been developed to gauge the extent to which conceptually driven processes mediate performance on indirect tests of memory (e.g., see Masson \& Freedman, 1990; Weldon, 1991). The logic behind this strategy is straightforward. If changing the semantic context at retrieval does not reduce performance relative to conditions in which the semantic context is unchanged, then the implication is that the memory test of interest is data driven. Because the perceptual (in this case, visual) features of the target event remain intact regardless of the variation in semantic context, data-driven processes would be equally supportedin all conditions. On the other hand, if changing semantic context from encoding to test produces lower performance than when semantic context is maintained, then one can infer that conceptually driven processes are involved in the memory task (see Masson \& Freedman, 1990).

Following the reasoning just described, we expected the following possible outcomes. If prospective memory is a conceptually driven task, then prospective memory performance should decline with changes in semantic context. Alternatively, if prospective memory is mediated primarily by data-driven processes, then prospective memory performance should not be affected by the semantic context change.r

\section{Method}

Subjects. Seventy-two undergraduate students at Purdue University participated in this experiment for extra credit for a psychology course. Twenty-four subjects were randomly assigned to each of the three conditions in which the retrieval conditions were the same, modulated, or different from those at encoding. The subjects were tested individually.

Materials and Procedure. The subjects were required to perform several tasks that will be described for purposes of exposition in terms of three phases. The first phase served to instantiate a given homographic meaning for the prospective memory target word bat, chest, or pool by embedding the target word in a sentence that biased one homographic meaning. Specifically, the subjects were told that the primary interest of the study was to examine how they verify the truth of different types of sentences. They were told that a sentence would appear in the middle of the computer screen, and, after reading each sentence, they should indicate whether the statement was true or false by pressing the appropriate key on the keyboard (a truth verification task similar to that used by Gick, Craik, \& Morris, 1988). After the key was pressed, the next sentence appeared on the screen. The subjects were told that they would be doing a similar task at the end of the experiment (Phase 3 ). The subjects were then presented with five practice trials to familiarize them with the procedure. Two of the first four sentences were false, and two were true. The fifth sentence, which was always true, contained the prospective memory target word. This prospective memory encoding sentence was chosen from four possible sentences constructed for each of the three possible target words (each subject was presented with only one target word and one target sentence). Two sentences instantiated each homographic meaning of the target words, and each sentence embedded the target word in a different situation. Appendix A provides the list of sentences used to support encoding of the prospective memory target words. Each prospective memory encoding sentence appeared equally often across subjects. After verifying the last sentence, the subjects were told that a secondary interest of this study was to examine their ability to remember to do something in the future. They were told that if they ever saw the word bat again (or chest or pool, depending on the particular target used), they should press a particular key (the Fl0 key) on the keyboard.

On the basis of previous work (Einstein \& McDaniel, 1990), we implemented a delay between the prospective memory instruction and the actual sentence verification trials in order to produce sufficient prospective memory forgetting. During this delay, the subjects were first given intentional learning instructions for a free recall task and then presented with a randomized list of 36 items ( 6 items from 6 categories). These words were chosen from the Battig and Montague (1969) norms, and each word was presented in the center of the computer screen for $4 \mathrm{sec}$. After all the items were presented, the subjects were given $3 \mathrm{~min}$ to recall the items from the list. Next, the subjects were given intentional learning instructions for a recognition test and were presented with a list of 56 words from the Battig and Montague norms ( 1 familiar item from each of the 56 categories). Each word was presented in the middle of the computer screen for $2 \mathrm{sec}$. After all the items were presented, the subjects were given a recognition test consisting of 56 old items randomly intermixed with 56 new items (chosen in the same manner as the old items). The subjects were allowed $5 \mathrm{~min}$ to circle all the old items.

During the third phase, the prospective memory test was embedded within the same truth verification procedure presented in the first phase. The subjects were told that they would now perform the truth verification task practiced at the beginning of the experiment. There was no mention of the prospective memory instructions. In order to create sufficient cognitive load during the truth verification task so as to avoid ceiling effects in prospective memory performance, the subjects were given a task in addition to sentence verification. They were told that after responding to the last sentence in each block (sentences were presented in blocks of 6), they should report the last word of each sentence in the original serial order of presentation. The subjects were given as much time as needed to report the words.

The subjects saw nine blocks of sentences. The first block served to refamiliarize the subjects with the procedure. The next eight blocks contained the prospective memory target word in four of the blocks. The specific block in which the target word appeared was determined randomly in order to prevent the subjects from detecting a pattern and anticipating the occurrence of the target word. Within each block, the particular sentence containing the target word was also determined randomly. The target word was never the last word in the sentence, and the target sentence was never the last one in a block.

The type of sentence (same, modulated, or different semantic context from that encountered at encoding) was manipulated between subjects; thus, the particular target sentences that each participant received depended on condition. In all three conditions, the words in the target sentences were different (except for the target word and some function words) from those used in the original encoding sentence. Each of the four target sentences was worded differently as well. Appendix B provides examples. The modulated sentences were created such that the meaning of the target word remained the same from the first to the third phase, but the attributes 
Table 1

Recognition, Recall, and Sentence Verification Times in Experiment 1

\begin{tabular}{|c|c|c|c|c|c|c|}
\hline \multirow[b]{3}{*}{ Dependent Measure } & \multicolumn{6}{|c|}{ Prospective Memory Condition } \\
\hline & \multicolumn{2}{|c|}{ Same } & \multicolumn{2}{|c|}{ Modified } & \multicolumn{2}{|c|}{ Different } \\
\hline & $M$ & $S D$ & $M$ & $S D$ & $M$ & $S D$ \\
\hline Recognition $\left(A^{\prime}\right)$ & .90 & .05 & .91 & .06 & .83 & .06 \\
\hline Recall & .50 & .09 & .51 & .10 & .48 & .15 \\
\hline \multicolumn{7}{|l|}{ Verification Time* } \\
\hline Target sentences & 8.50 & 2.76 & 8.29 & 3.94 & 7.89 & 3.18 \\
\hline Filler sentences & 6.84 & 1.90 & 6.50 & 2.66 & 6.22 & 2.10 \\
\hline
\end{tabular}

*Verification times are in seconds

activated about that referent were changed. For example, during the first phase, the target word bat might occur in the sentence, "You might find a bat sleeping in a dark cave"; however, during the third phase, it might occur in the sentence, "A bat travels from place to place by flying through the air."

Each subject saw four target sentences (all of which were worded to reflect the particular retrieval condition to which a subject was assigned), two in a true form and two in a false form. The order in which each subject received each form was random. In order to avoid the alerting consequence of only one word being repeated four times, the filler sentences also contained words that were repeated across blocks. These words were also seen during the first phase in order to avoid any effects of familiarity (see Robinson, 1992, for experimental target and filler sentences).

\section{Results and Discussion}

Prospective memory. The rejection level for all analyses reported throughout this paper was set at .05 . To assess prospective memory performance, the proportion of correct responses was tabulated (out of 4 possible). ${ }^{1}$ A response was scored as correct if the subject remembered to press the response key sometime between the occurrence of the target event and the end of the block of trials in which it occurred. The mean prospective memory performances for the same, modulated, and different conditions were $.81, .54$, and .48 , respectively. A between-subjects analysis of variance (ANOVA) revealed that prospective memory performance varied significantly as a function of retrieval condition $\left[F(2,69)=4.14, M S_{\mathrm{e}}=0.18\right]$.

Pairwise comparisons revealed that prospective memory performance was better in the same condition than in either the different condition $\left[F(1,63)=7.31, M S_{\mathrm{e}}=0.18\right]$ or the modulated condition $\left[F(1,63)=4.89, M S_{\mathrm{e}}=0.18\right]$. Performance in the modulated condition was not significantly different from that in the different condition $(F<1)$. Considering prospective memory responding on an individual trial basis in the same condition, $71 \%$ of the subjects responded on all four trials, $12 \%$ forgot on all four trials, and $17 \%$ responded on one, two, or three of the trials. In contrast, in the modulated and different conditions, nearly as many forgot on all four trials $(38 \%$ and $33 \%$, respectively) as responded on all four trials ( $42 \%$ and $33 \%$, respectively). Finally, $20 \%$ of the subjects in the modulated condition and $33 \%$ in the different condition responded on one, two, or three trials.

These results clearly show that a change in the meaning of a word from encoding to retrieval has a detrimental ef- fect. Thus, successful prospective memory seems to depend on the match between the encoded meaning of the target event and the target event's meaning when it is encountered. Viewed from a different perspective, this finding shows that a perceptually identical representation of the prospective memory target event was not sufficient to support a given level of prospective remembering. The present result implies that prospective remembering is based on conceptually driven processes. More extensive discussion of this conclusion will be delayed until we report two additional experiments.

Retrospective memory and cover task performance. Table 1 displays the means for recognition $\left(A^{\prime}\right.$ scores; Donaldson, 1992), free recall performance, and the time to verify the truth value of the sentences.

A single factor (with same, modulated, and different conditions as the levels) between-subjects ANOVA was computed for each measure to confirm that the prospective memory manipulation had no influence on the other tasks in the experiment. There was no significant effect of condition in recognition performance, free recall performance, or response times in the truth verification task for sentences that included a prospective memory target or for filler sentences (all $F \mathrm{~s}<1$ ). There were no errors in truth verification responding.

To determine whether there was a relation between the retrospective memory tests and prospective memory performance, we computed correlations between each retrospective test score and prospective memory performance. These correlations were computed separately for each experimental condition because the experimental manipulation affected prospective, but not retrospective, memory. Consistent with previous work (e.g., Einstein \& McDaniel, 1990), there was little evidence that prospective memory performance was consistently related to the retrospective memory tasks. For recognition and prospective memory performance, the Pearson correlation coefficient was significant for the different condition $[r(22)=.45]$, but not for the same condition $[r(22)=.01]$ or the modulated condition $[r(22)=.35]$. For recall and prospective memory performance, the correlation was significant for the modulated condition $[r(22)=.42]$, but not for the same condition $[r(22)=.30]$ or the different condition $[r(22)=.07]$.

\section{EXPERIMENT 2}

In Experiment 2, the prospective memory task was again embedded in the context of a sentence verification task; however, we used another set of manipulations that has been exploited in the retrospective memory literature as markers of conceptually driven and data-driven processes. Specifically, we manipulated the format in which the prospective memory target event appeared at encoding and at test. During the encoding phase, the target event was presented as either a word or a picture. Factorially combined with this encoding format manipulation, the format of the target event during the prospective memory test phase was also presented as a word or a picture. Varying 
the prospective memory target at encoding as pictures or words also provides important leverage on the issue raised earlier regarding the similarity of prospective remembering to performance on direct retrospective tests versus indirect memory tests. This aspect will be amplified below.

Alternative patterns were expected depending on whether prospective memory is relatively more conceptually driven or data-driven. These expectations are based on characteristic patterns obtained on various kinds of retrospective memory tests when format (picture, word) is varied at encoding and at test. Memory tasks that rely on conceptual information (e.g., free recall, recognition) show a robust advantage when encoding involves processing of pictures rather than processing of words (Paivio, 1971; Paivio \& Csapo, 1973; Shepard, 1967). This "picture superiority" effect is large for explicit conceptually driven tests, and holds even when the test cues are nonpictorial (e.g., a recognition test with words as test items). More specifically, Brown, Neblett, Jones, and Mitchell (1991, Experiments 1 and 5), using recognition, varied both the format at encoding (pictures, words) and at test and found the following ordering from best to worst performance: picture-picture, picture-word, word-word, word-picture. We expected that, if prospective remembering is relatively conceptually driven, then a clear advantage of picture encoding should obtain. Importantly, if an advantage of picture encoding were to obtain, then prospective memory could be characterized as behaving like conceptually driven direct memory tasks but not like conceptually driven indirect memory tasks. This statement is based on recent reports that pictures produced an advantage over words for direct recall tests (cued and free) but not for indirect conceptually based tests (category instance generation and word association; McDermott \& Roediger, 1996, Experiment 2; Weldon \& Coyote, 1996). Moreover, if the ordering of means paralleled that reported by Brown et al., then this would be further convergence for the idea that the processing underlying prospective memory is similar to that underlying cued direct memory tests (see Einstein \& McDaniel, 1990; McDaniel \& Einstein, 1993).

In contrast to the pattern displayed by direct conceptually driven tasks, for data-driven tests (e.g., fragment completion tasks), performance is best when the cue presented at test overlaps with the format (pictorial or lexical information) that was presented during encoding (e.g., Brown et al., 1991; Weldon \& Roediger, 1987; Weldon, Roediger, $\&$ Challis, 1989). When the cue present at test does not overlap with the format seen during encoding, then performance declines significantly, and, in some cases (e.g., indirect tests of memory, like completion tasks), the decline is so substantial that there is almost a complete absence of priming (e.g., Weldon \& Roediger, 1987, Experiment 4; Weldon et al., 1989, Experiment 1). A further hallmark of these data-driven tests is that there is typically a crossover interaction between encoding and test format such that there is no significant main effect of encoding format. In particular, there is no advantage of picture encoding over word encoding (e.g., Weldon et al., 1989, Experiment 3).
On the basis of these findings, we reasoned that, if prospective remembering were largely data driven, then prospective memory performance should be best when the encoding and retrieval formats matched (word-word, picture-picture) and significantly reduced when the encoding and retrieval formats mismatched (word-picture, picture-word). Additionally, the form of this interaction should be such that picture encoding should not uniformly produce better performance than word encoding. In particular, data-driven processes would be implicated if picture encoding were associated with low levels of prospective remembering relative to word encoding when the test event was presented as a word. Finally, it could be that a pattern associated with data-driven processes would not emerge, yet picture and word encoding would still produce fairly equivalent performance. This pattern would suggest a similarity between performance on indirect conceptual tests (McDermott \& Roediger, 1996, Experiment 2; Weldon \& Coyote, 1996) and prospective memory performance.

Toward the objective of gaining a more comprehensive understanding of prospective memory processes, in Experiment 2 we also manipulated the environmental context in which encoding and retrieval occurred. The encoding and retrieval sessions were conducted either in the same laboratory room or in different rooms. A priori, several theoretically informative outcomes associated with this environmental context reinstatement manipulation seemed possible. One approach to gaining leverage on the processes involved in prospective memory has been to draw parallels between a recognition test and the kind of prospective memory task investigated herein (Einstein \& McDaniel, 1996; McDaniel, 1995). Briefly, the idea is that processing the copy cue on the recognition test or the target event on the prospective memory task activates feelings of familiarity and also a search to provide information about the significance of the cue (or, in recognition, the search would attempt to recover the context in which the item occurred, thus enabling an accurate recognition judgment). For present purposes, the important observation is that positive effects of reinstating environmental context are generally not found in recognition (Eich, 1985; Godden \& Baddeley, 1980; S. M. Smith, Glenberg, \& Bjork, 1978). Thus, to the extent that recognition and prospective remembering entail overlapping processes, there should be an absence of environmental context effects on prospective remembering.

A more complex prediction emerges when one considers the possible joint effects of the environmental context manipulation and the encoding format (picture, word) manipulation. One view of environmental context effects, the outshining hypothesis (S. M. Smith, 1988), suggests that the benefits of environmental context emerge only when more effective retrieval routes for accessing the target information are not available (see also McDaniel, Anderson, Einstein, \& O'Halloran, 1989). For a conceptually based memory task, such routes would be created by elaborative encoding activities like those presumably engaged when 
Table 2

Memory Performance in Experiment 2

\begin{tabular}{|c|c|c|c|c|c|c|c|c|c|}
\hline \multirow{4}{*}{$\begin{array}{l}\text { Dependent } \\
\text { Measure }\end{array}$} & \multirow{4}{*}{$\begin{array}{c}\text { Environmental } \\
\text { Context }\end{array}$} & \multicolumn{8}{|c|}{ Encoding Format } \\
\hline & & \multicolumn{4}{|c|}{ Word } & \multicolumn{4}{|c|}{ Picture } \\
\hline & & \multicolumn{2}{|c|}{ Word* } & \multicolumn{2}{|c|}{ Picture } & \multicolumn{2}{|c|}{ Word } & \multicolumn{2}{|c|}{ Picture } \\
\hline & & $M$ & $S D$ & $M$ & $S D$ & $M$ & $S D$ & $M$ & $S D$ \\
\hline \multirow{2}{*}{ Prospective Memory } & Same & .67 & .44 & .62 & .49 & .67 & .52 & 1.00 & .00 \\
\hline & Different & .50 & .55 & .08 & .20 & .96 & .10 & 1.00 & .00 \\
\hline \multirow[t]{2}{*}{ Recognition $\left(A^{\prime}\right)$} & Same & .91 & .04 & .87 & .05 & .91 & .05 & .86 & .03 \\
\hline & Different & .91 & .04 & .89 & .04 & .90 & .06 & .90 & .08 \\
\hline \multirow[t]{2}{*}{ Recall } & Same & .47 & .15 & .48 & .14 & .46 & .17 & .35 & .11 \\
\hline & Different & .42 & .17 & .41 & .10 & .38 & .13 & .46 & .13 \\
\hline
\end{tabular}

*Retrieval format.

pictures are presented during study (Nelson, 1979; M. C. Smith \& Magee, 1980). In line with the just-mentioned ideas, McDaniel et al. (1989) reported that context dependency effects in free recall were more likely to emerge after verbal encoding than after visual imagery encoding of target sentences. Accordingly, assuming the outshining hypothesis, if prospective memory is primarily conceptually based, then the effects of environmental context should be limited to the word encoding condition (the condition associated with relatively less elaborative encoding). That is, on this view, there should be a two-way interaction of the encoding format (picture, word) and the match of environmental context at encoding and at retrieval, such that matching environmental context at encoding and retrieval enhances prospective memory (relative to the mismatched context) when the encoded target is a word but not when the encoded target is a picture.

\section{Method}

Subjects and Design. Forty-eight undergraduate students at Purdue University participated in Experiment 2 in partial fulfillment for an introductory psychology course. Six subjects were randomly assigned to each of the eight conditions formed by the factorial manipulation of the encoding format of the prospective memory target event (picture, word), the test format of target event (picture, word), and the environmental context at retrieval (same room as encoding, different room).

Procedure. The procedure for Experiment 2 was identical to that used in Experiment 1, with several exceptions as noted below. The meaning of the three target words was limited to a treasure chest, a bat used in a baseball game, and a pool used for the activity of swimming (note that each subject received only one of the three target items); the same meaning was preserved across encoding and test. For Phase 1, during which the prospective memory target event was encoded, a given format was instantiated for the target event by performing the truth verification task as in Experiment 1. The only change was that the first four sentences consisted of two concepts in a picture format and two concepts in a word format. One of each was true, and one of each was false. The format of the target word in the last sentence depended on condition (word or picture format). The subjects were told to knock twice on the table when they saw the target. They were told to knock twice rather than press a key on the keyboard (as in Experiment l) because the sentences were presented one at a time in a large binder rather than on the computer screen (this change was implemented for manipulation of target format, and, due to this change, verification times for the sentences were not recorded). Once the last sentence (the target sentence) was removed from the subjects' view, they were instructed to knock when they encountered the concept bat (or chest or pool) again. This instructional procedure was piloted such that it would not bias the subjects to necessarily expect either a word or a picture at test. During postexperimental questioning, we asked the subjects if they thought that they were not supposed to respond if bat was a word (or picture depending on the encoding condition). No subjects indicated that they believed they were not supposed to respond because of the particular format in which the target was presented.

Encoding took place in a spacious room with stark white walls or in a very small room with brightly colored posters on the walls. The particular room used for encoding was completely counterbalanced across the environmental context factor (same, different room). The same recall and recognition tasks as in Experiment 1 were used as distractors between encoding and test (i.e., Phase 2).

During the third phase, the subjects encountered the target event in four different sentences in either a word or a picture format, depending on the experimental condition. All of the filler sentences for the word condition were composed entirely of words, and all of the filler sentences for the picture test condition contained one picture. In order to avoid the alerting consequence of a word (or picture) being repeated four times, the filler sentences also contained words (or pictures) that were repeated across blocks. Specifically, each of six nontarget words (pictures) were used in four different nontarget sentences, thereby producing 24 nontarget sentences that included repeated items. The remaining 26 nontarget sentences contained nonrepeated words (pictures).

In addition, the subjects performed the Phase 3 truth verification task in the same room in which they had participated in the first two phases of the experiment or in a different room. In the differentroom condition, the subjects were told that the lab was needed by another experimenter and that the rest of the experiment would be completed in another room. The subjects were then taken next door to the other experimental room. If the subjects performed the task in the same room, they were told that the next phase of the experiment must be set up and that they needed to leave the room while this was done. After a few minutes (equivalent to the amount of time it took to walk next door in the change condition), the subjects were told to come back into the room to finish the experiment. This room change took place after the subjects had completed the recall and recognition tasks.

\section{Results and Discussion}

Prospective memory. The proportion of correct responses (out of four) was tabulated, and the means are displayed in Table 2. A response was scored as correct if the subjects remembered to knock sometime between the occurrence of the target event and the end of the block of trials in which it occurred. A three-factor between-subjects ANOVA including the variables of encoding format (pictureword), retrieval format (picture-word), and environmental retrieval context (same or different room) was used to ana- 
lyze these data. A main effect of encoding format $[F(1,40)=$ 17.43, $M S_{\mathrm{e}}=0.13$ ] indicated that picture encoding produced better prospective remembering than did word encoding (.91 vs. .47). Retrieval format had no effect on performance $(F<1)$, and there was a marginally significant interaction between encoding and retrieval format $[F(1,40)=$ $3.95, p<.06]$. As can be seen in Table 2 , the tendency was for prospective memory performance with a given retrieval format (picture or word) to be better when the encoding and retrieval formats matched (picture-picture or word-word) than when they mismatched (picture-word or word-picture).

The subjects generally remembered the prospective memory task on all trials or forgot the task on every trial, with the proportion of subjects in these two categories systematically changing across condition. One hundred percent of the picture picture subjects, $75 \%$ of the pictureword subjects, $50 \%$ of the word-word subjects, and $25 \%$ of the word-picture subjects responded on all four trials. None of the picture-picture subjects, $17 \%$ of the picture-word subjects, $33 \%$ of the word-word subjects, and $58 \%$ of the word-picture subjects forgot on all four trials. Few subjects responded on only one, two, or three of the trials, with $8 \%$ doing so in the picture-word condition and $17 \%$ doing so in the word encoding conditions.

Though the perfect performance observed in the picturepicture condition possibly prevented the encoding retrieval format interaction from reaching standard levels of significance, this ceiling effect does not obscure the critical aspect of these results regarding the theoretical issues outlined in the introduction. In particular, a robust picture superiority effect emerged, and, importantly, the advantage for picture encoding tended to be maintained even when the surface features of the retrieval format were not pictorial. That is, when the retrieval format was a word, picture encoding still produced equivalent (same environmental context) or better (different environmental context) prospective remembering than did word encoding, despite the fact that word encoding allows complete overlap between surface features at encoding and retrieval (for the word retrieval condition). This pattern is consistent with theoretical expectations for a conceptually based memory task, expectations that have been verified with conceptually driven retrospective tasks (e.g., Brown et al., 1991, though see McDermott \& Roediger, 1996, Experiment 2, and Weldon \& Coyote, 1996, for exceptions with indirect conceptual memory tests). Therefore, the results support the general implication from our previous experiment that prospective remembering is a conceptually driven process.

Recent work has suggested that direct and indirect conceptually driven tasks may themselves not be entirely similar (McDermott \& Roediger, 1996), inasmuch as direct conceptual tests (cued recall) reveal a picture superiority effect, whereas indirect conceptual tests do not (Weldon \& Coyote, 1996). Therefore, the picture superiority effect obtained here further suggests that prospective remembering is more closely aligned with processes involved in direct, rather than indirect, retrospective conceptually driven tests. (Experiment 3 below provided additional leverage on this issue.)

Although there was not a significant main effect of environmental context $(F<1)$, there was a significant interaction between encoding format and environmental context $\left[F(1,40)=5.69 M S_{\mathrm{e}}=0.13\right]$. Examination of Table 2 shows that this interaction reflected better performance in the same-context condition than in the different-context condition (i.e., there was a context reinstatement effect) when the format of the target during encoding was a word $[F(1,40)=5.98, p<.05]$, but not when the format during encoding was a picture $[F(1,40)=1.04]$. Indeed, with picture encoding, there was a nominal advantage for the different context relative to the same context.

The foregoing pattern is completely in line with the prediction that environmental reinstatement would be mnemonically important only when effective retrieval routes were less available for supporting prospective remembering. On the basis of the convergent results that a prospective memory task is conceptually based, encoding a picture target event would afford more effective retrieval routes for encoded intentions (because pictures presumably promote more elaborative processing than do words; Nelson, 1979; M. C. Smith \& Magee, 1980) and thereby obviate the need for alternative retrieval routes mediated by environmental cues. In contrast, when words are presented during encoding, elaborative encoding for the target event is presumably reduced so that retrieval routes are less rich or numerous (cf. Anderson \& Reder, 1979). In this case, the additional cues provided by environmental reinstatement would become useful.

Retrospective memory. As in Experiment 1, there were no errors on the truth verification task. Recognition performance was assessed by computing $A^{\prime}$ scores, and free recall performance was assessed by calculating the proportion of words correctly recalled. A three-factor between-subjects ANOVA was computed for each memory measure to investigate whether the prospective memory conditions (encoding format, retrieval format, and environmental retrieval context, same or different room), which were not operational for the retrospective memory measures, were associated with performance on this portion of the experiment. For recognition, there were no significant main or interaction effects [largest $F(1,40)=1.66$, $\left.M S_{\mathrm{e}}=0.001\right]$. For recall, there were also no main or interaction effects [largest $F(1,40)=1.99, M S_{\mathrm{e}}=0.02$ ].

Correlations between prospective memory performance and the retrospective memory tasks were computed for the groups representing the factorial combination of the encoding format and retrieval format (except for the picturepicture group due to perfect performance in prospective memory) as well as for the groups representing the factorial combination of encoding format and environmental context (because of the interactive effects of these variables on prospective memory but not retrospective memory). Only one of the correlations between recognition and prospective memory performance was significant $[r(10)=$ 
-.69 , for the picture encoding group with the same environmental context at study and test; the other correlations ranged from -.56 to -.11 ]. The correlations between recall and prospective memory performance were not significant (ranging from -.35 to .17 ).

\section{EXPERIMENT 3}

To provide further convergence for the more circumscribed idea that prospective remembering reflects processes similar to those underlying direct conceptual retrospective memory tests, we used an entirely different experimental approach, and we additionally modified the details of the prospective memory task. In Experiment 3, one manipulation was the level of processing at encoding of two prospective memory target words. Increased memory performance for semantically processed items relative to nonsemantically processed items (a levels-of-processing effect) is taken to reflect a memory task that relies on conceptually driven processes, whereas equivalent memory performance for semantically and nonsemantically processed items is assumed to reflect a data-driven memory task (see Roediger et al., 1989).

The second, critical, manipulation involved either dividing attention or not dividing attention during the presentation of the ongoing activity (a pleasantness rating task) in which the prospective memory responses were supposed to occur. Performance on direct retrospective tests, such as recall, is assumed to be supported by processes of conscious recollection, and such memory processes are thought to be supported by controlled attentional resources (Jacoby, Woloshyn, \& Kelley, 1989). Dividing attention is assumed to reduce the contribution of controlled processes, thereby reducing performance on memory tests (e.g., direct retrospective tests) that involve conscious recollection. Thus, reduced prospective memory performance under divided-attention conditions (relative to fullattention conditions) would suggest that prospective memory involves conscious recollection. On the other hand, if prospective memory is not attenuated by dividing attention, then it would imply that prospective remembering is not similar in this regard to conceptually driven direct memory tests such as recall (Craik et al., 1996).

\section{Method}

Subjects and Design. The subjects were undergraduate students at Furman University and Purdue University participating in partial fulfillment of a course requirement or for extra credit. Thirty subjeets were randomly assigned to each of the four experimental conditions; in each condition, 12 of the subjects were from Furman and 18 were from Purdue. The four experimental conditions were formed by the factorial combination of encoding level (semantic, nonsemantic) and attention available at test (full, divided).

Materials. All 230 words for the word lists described in the following section were nouns selected from Cluster 7 (indicating highrated values on rated dimensions) of the Toglia and Battig (1978) corpus. This cluster is composed of 566 words, with the mean ratings of the words (on a scale of 1-7, with 7 indicating higher ratings on a particular dimension) as follows: concreteness, 5.65 ; imagery,
5.49; categorizability, 5.34; meaningfulness, 4.75 ; familiarity, 5.74; number of attributes, 3.48 ; and pleasantness, 3.70 .

Procedure. To begin the experiment, the subjects were instructed that they would be required to study four 20 -item word lists and that, for each word list, they would receive a recall test. For each list, words were presented individually on a CRT monitor at a rate of $4 \mathrm{sec}$ per word. The important procedural aspect here is that half of the words in each list were displayed in black print and half in red print. This was done so that the subsequent prospective memory encoding phase (in which red print was used to display the two prospective memory target words) would not create undue surprise or distraction. That is, these four word lists were presented simply to habituate the subjects to seeing some words in red print. After each list was presented, the subjects were given 2 min to recall words from the just-presented list. The subjects recorded the words that they recalled on a sheet of paper. A beep emitted from the computer indicated the end of the 2-min recall period and the presentation of the next word list

After completing the last recall test, the subjects were informed that the next phase of the experiment consisted of five tasks (adjective generation, rhyming, vowel counting, imagery, and pleasantness rating). The subjects were given an overview of all five tasks and were informed that they would be given instructions again before each task. The first task (either the rhyme task or the adjective task depending on the experimental condition to which the subject was assigned) was directed at manipulating the level at which the subjects processed the prospective memory target event. To do so, two prospective memory target words ( fan and cave) were embedded in a list of words in which the subjects were required to generate an adjective for each word (semantic encoding) or generate a rhyme for each word (nonsemantic encoding). To exert as much control over the level of processing as possible, we required the subjects to perform the assigned orienting task on a 30 -item list, with each of the two prospective memory target words embedded in the middle of the list and displayed in red print. The subjects were told to write down a rhyme (adjective) for each of the words in the list. Just prior to receiving this list, the subjects were instructed,

By the way, within this first list of words you will see some words colored in red. I want you to pay close attention to these words because later on they will appear again in the pleasantness task. When they do, they won't be colored red, but they will still be the same words. When you see the words in the pleasantness task, I want you to reach over and press the F10 key.

If there were no questions, the experimenter initiated presentation of the word list on the monitor. The words were presented one at a time in subject-paced fashion (this procedure was followed for all of the tasks in this part of the experiment). Once the subject had written down a rhyme (adjective), he or she pressed the space bar on the keyboard to proceed to the next word.

Having processed the first list, the instructions for the next list were presented (all of the subsequent lists were composed of 30 words, except the final list, which was composed of 64 words). The subjects who generated rhymes on the first list, generated adjectives on the second list; the subjects who generated adjectives on the first list, now generated rhymes. Next, the third list was presented, and the subjects were instructed that they would use the number pad from here on to respond. They were asked to press the key that corresponded to the number of vowels in each word; doing so, initiated presentation of the next word. After completing the vowel counting task, the subjects were instructed that, in the next list, they were to construct a picture (image) in their mind of the referent of each word. They were further instructed that after constructing the image, they should enter a vividness rating for their image on a scale of $1-5$, with 1 representing an image that was not vivid and 5 representing a perfectly vivid image. Entering the imagery rating initiated the pre- 
Table 3

Proportions of Prospective Memory Responses and Pleasantness Ratings and Rating Times in Experiment 3

\begin{tabular}{|c|c|c|c|c|c|}
\hline & \multicolumn{4}{|c|}{ Retrieval Condition } & \multirow[b]{3}{*}{$M$} \\
\hline & \multicolumn{2}{|c|}{ Full Attention } & \multicolumn{2}{|c|}{ Divided Attention } & \\
\hline & $M$ & $S D$ & $M$ & $S D$ & \\
\hline \multicolumn{6}{|l|}{ Encoding Task } \\
\hline Adjective & .55 & .39 & .28 & .39 & .42 \\
\hline Rhyme & .40 & .39 & .18 & .33 & .29 \\
\hline$M$ & .48 & & .23 & & \\
\hline \multicolumn{6}{|c|}{ Pleasantness Rating } \\
\hline \multicolumn{6}{|c|}{ Ratings } \\
\hline Adjective & 2.8 & .28 & 2.7 & .42 & \\
\hline Rhyme & 2.8 & .34 & 2.9 & .47 & \\
\hline \multicolumn{6}{|l|}{ Times* } \\
\hline Adjective & 2.75 & .57 & 3.83 & 1.27 & \\
\hline Rhyme & 2.80 & .63 & 3.49 & 1.08 & \\
\hline
\end{tabular}

*Rating times are in seconds.

sentation of the next word. These three intervening tasks (rhyme or adjective generation, vowel counting, and imagery rating) served as distractors to clear the prospective memory instruction from working memory and to ensure that prospective memory performance was not at ceiling. No nouns were repeated across these lists.

For the final task, the subjects were reminded that they would have to rate the pleasantness of each word on a scale of $1-5$, with 1 representing the least pleasant and 5 representing the most pleasant. The subjects were not reminded about the prospective memory response that was embedded in this task. Each prospective memory target item was presented twice in the pleasantness-rating list, for a total of four prospective memory trials. To preclude the possibility that these targets might attract attention simply because they were the only words repeated across lists, 30 words from the previous four 30 -item lists ( 8 from the first list, 7 from the second list, 9 from the third list, and 6 from the fourth list) were also included in the pleasantness-rating list. These words were intermixed with a set of 30 words selected from the same corpus but not previously seen in the experiment.

After reviewing the pleasantness-rating instructions, all subjects were informed that they would also be listening to an audio tape of random numbers. Even full-attention subjects were given this instruction so that any possible interference that this instruction might have on prospective memory would be equated across attentional conditions. They were instructed to listen for three odd numbers in a row and, when this occurred, to respond verbally with the word now. The subjects in the divided-attention conditions were told that they would be performing the digit monitoring task along with the pleasantness task, whereas the subjects in the full-attention condition were told they would be doing the digit monitoring task later. All subjects then initiated the pleasantness-rating task by pressing the space bar, and, simultaneously, the experimenter started the audio tape for the subjects in the divided-attention condition.

\section{Results and Discussion}

The proportion of prospective memory responses (number of times the subjects remembered to press the F10 key out of four possible opportunities) was subjected to a $2 \times 2$ (levels of processing by attention) between-subjects ANOVA. As can be seen in Table 3, dividing attention during testing substantially reduced prospective memory performance relative to the full-attention condition $[F(1,116)=$ 12.95, $\left.M S_{\mathrm{e}}=0.14\right]$. Furthermore, generating an adjective to the prospective memory target event at encoding tended to produce better prospective remembering than did generating a rhyme at encoding $[F(1,116)=3.58, p<.10]$, and this advantage was apparent in both the full-attention condition and divided-attention condition $(F<1$, for the interaction).

Conceptually driven memory tasks have been identified operationally as tasks that reveal levels-of-processing effects (Roediger et al., 1989), and a marginally significant levels-of-processing effect was obtained for prospective remembering. If prospective memory were purely data driven, then there should have been no noticeable advantage for semantically encoded words over nonsemantically encoded words (Roediger et al., 1992). Thus, the pattern of results is most consistent with the notion that prospective memory performance, at least for the kind of task implemented here, is conceptually driven.

Importantly for present purposes, dividing attention during test substantially reduced prospective memory performance. This implies that control processes associated with conscious recollection are involved in prospective remembering. This claim is based on the argument that divided attention (at test) disrupts controlled processes involved in conscious recollection (e.g., Jacoby et al., 1989). Craik et al. (1996) also found reductions in memory performance when attention is divided at retrieval for explicit retrospective tasks that would presumably require controlled processes (e.g., free and cued recall). Because conscious recollection is presumed to be involved in direct, but not indirect, tests of memory, the present divided-attention effect and levels-of-processing trend thus converge with the idea that prospective remembering shares prominent components with direct conceptual retrospective tests. Still unclear, however, is what retrieval processes are compromised by dividing attention (cf. Craik et al., 1996); we will address that issue in the General Discussion that follows.

The response time and pleasantness-rating responses for all the words presented in that task (for 24 subjects in each group $)^{2}$ were analyzed with separate between-subjects ANOVAs paralleling those computed for the prospective memory responses (see Table 3 for means). Response times were significantly longer in the dividedattention condition than in the full-attention condition $\left[F(1,92)=40.20 ; M S_{\mathrm{e}}=875,102\right.$, for times in milliseconds]. For the pleasantness ratings, there were no significant effects.

\section{GENERAL DISCUSSION}

A central objective for increasing our understanding of prospective memory is to determine the processes that support activation of the to-be-performed action when the rememberer encounters the target event (e.g., activating your intention to give a message to a friend upon seeing that friend, or activating your intention to press a designated key on the keyboard upon encountering a particular word). The goal of this research was to make progress toward that objective by investigating whether prospective remembering is a primarily conceptually driven activity or a data-driven 
retrieval activity. Across a number of manipulations that have been exploited in the retrospective memory literature as markers of conceptually driven and data-driven processes, we obtained convergence for the conclusion that prospective remembering is conceptually based. Furthermore, manipulations that have dissociated direct and indirect tests suggest that prospective remembering may recruit processes or systems associated with direct tests rather than indirect tests. We consider the evidence for each of these claims in turn and then sketch a possible model of the mechanisms involved in prospective memory.

Prospective memory performance tended to be enhanced when the target event was encoded semantically rather than nonsemantically (a levels-of-processing effect). A levels-of-processing effect is associated with conceptually driven memory tasks, but not necessarily data-driven memory tasks (cf. Roediger et al., 1989; Roediger et al., 1992). However, the levels-of-processing effect was marginally significant; therefore, on that effect alone, the conclusion that prospective remembering is primarily conceptually driven is not compelling. In some cases, marginally significant levels-of-processing effects have been reported for indirect memory tasks assumed to be relatively data driven (Challis \& Brodbeck, 1992).

Further support for the conceptual nature of prospective memory comes from two recent reports showing that generating the target word at encoding produces higher levels of prospective memory performance than does reading the target word at encoding (Matthews, 1992; RobinsonRiegler, 1994, Experiment 1). The generation effect is also typically associated with conceptual memory tasks but not data-driven memory tasks (Jacoby, 1983; see also Roediger et al., 1989). More direct support for the conceptual nature of prospective remembering was provided in Experiment 1, in which semantic context changes from the encoding to test significantly attenuated prospective memory. This finding parallels findings with conceptually based direct memory tests, such as cued recall. These studies, also using homographs (e.g., Goldstein, Schmitt, \& Scheirer, 1978; Hunt \& Ellis, 1974; Light \& Carter-Sobell, 1970), unequivocally showed the detrimental effects of changing the meaning of a word from encoding (strawberry jam) to retrieval (traffic jam).

The picture superiority effect reported in Experiment 2 provides additional evidence that more conceptual or elaborative encoding enhances prospective remembering. When words are presented at retrieval, the picture superiority effect has been reported only for direct conceptually based retrospective tasks; for data-driven tasks, picture superiority effects have not been reported. Importantly, picture superiority effects have so far not been found even for conceptually driven indirect tests (McDermott \& Roediger, 1996; Weldon \& Coyote, 1996), implying some differences between the processes on direct versus indirect conceptual tests. Accordingly, the picture superiority effect in prospective remembering may imply that the underlying conceptual processes are more closely associated with those manifested on direct tests than with those involved on indirect tests.
The effects of our divided-attention manipulation (Experiment 3) provides another line of evidence for the conclusion that the prospective memory tasks investigated here may involve conscious recollection processes like those in direct retrospective memory tasks. On retrospective tasks, dividing attention at retrieval typically reduces performance associated with conscious recollection components (e.g., search in recognition test; Jacoby et al., 1989). Dividing attention during the period when the prospective memory task was supposed to be initiated (retrieval of the intention) substantially reduced prospective memory performance, suggesting a process linked most closely to direct tests rather than to indirect tests, which do not involve conscious recollection.

Finally, the influence of environmental context on prospective remembering (Experiment 2) may also suggest similarities between prospective remembering and processes on direct retrospective tests. When the target event suggested a relatively impoverished encoding (i.e., a word format as opposed to a picture format), the environmental contextual cues facilitated the prospective memory process. One possibility for how this might occur is that, during encoding, the environmental cues become associated with the intended prospective memory activity, and, during test, reinstatement of these cues serves to provide some activation for the intended activity - activation that would be functional provided that the target event itself does not produce enough activation of the intended activity to make it consciously available (cf. Einstein \& McDaniel, 1996; McDaniel, 1995). These results and their interpretation dovetail with findings and views of context reinstatement effects on direct retrospective tasks (McDaniel et al., 1989; S. M. Smith, 1988), again establishing parallels between prospective memory performance and performance observed on direct retrospective tests (e.g., recall; McDaniel et al., 1989).

One outcome of establishing the conceptually driven nature of prospective memory, coupled with the suggestion that such processes seem more parallel to those in direct conceptual tests than in indirect conceptual tests (cf. McDermott \& Roediger, 1996; Weldon \& Coyote, 1996), is the delimitation of possible theoretical processes involved in prospective remembering. One idea outlined in the introduction was that prospective memory might be served by processes similar to those observed in data-driven indirect tasks because, in both cases, an external agent does not instruct the rememberer to attempt to recover previous episodic experiences. The present results suggest that the apparent formal similarities between a prospective memory task and standard kinds of indirect tests (i.e., data-driven) does not extend to the processes that underlie performance on these two types of memory tasks (cf. McDaniel $\&$ Einstein, 1993). What kind of account then might capture prospective remembering? We briefly consider a processing framework based on models of direct retrospective memory and then develop a model based on a systems approach to memory.

We (Einstein \& McDaniel, 1996; McDaniel, 1995) have previously suggested that prospective memory might be 
supported by two processes presumed to support recognition: an implicit familiarity process that is perceptually based (see Jacoby, 1984; Mandler, 1980) and a more directed memory search. Briefly, the idea is that prospective memory may involve in part a process much like contextfree recognition in which a person spontaneously experiences a sense of familiarity when encountering an environmental event (e.g., upon seeing a particular person on a bus; see Mandler, 1980), which in turn prompts a conscious search for the significance of the event (the search might eventually yield the solution that the person is my butcher). We had speculated that prospective remembering might similarly be stimulated by a familiarity process that is triggered by the appearance of the target event (e.g., seeing the person to whom you want to give a message). Our present results, however, converge with those reported by Guynn, McDaniel, and Einstein (in press) in countering the idea that a perceptually driven familiarity process plays a large role in prospective remembering.

One objection to this conclusion might be that it is the completion of an explicit component of the prospective memory task that is reflecting the influence of our experimental variables, and, therefore, the operation of more perceptually driven implicit processes could possibly be masked. ${ }^{3}$ Specifically, the idea is that the content of the intention (e.g., knock on the table) must be explicitly remembered for successful completion of the prospective memory task. If the content of the intention is not remembered, then even if some implicit perceptually driven process were giving rise to a sense of familiarity or significance for the target event, prospective remembering would not be evidenced. The present study does not bear directly on this possibility, but the content of the intention was purposefully designed to be minimally demanding for memory. The experiments were constructed so that prospective memory failures would most likely be due to the subjects' forgetting, at the moment that the target event appeared, that they had intended to do something (rather than forgetting the content of what they intended to do). In previous work with comparable minimally demanding content, recall tests and questionnaires given after performance of the prospective memory task revealed that the content is remembered by nearly all or all subjects (Einstein, Holland, McDaniel, \& Guynn, 1992). Accordingly, though possible, we believe it is unlikely that the present results reflect effects of the experimental manipulations solely on the processes involved in remembering the content per se of the intended action.

This reasoning leads us to propose an alternative model of prospective memory inspired by a systems view of memory. This orientation generally suggests that classes of memory tasks are subserved by particular systems (usually associated with neurological subtrates; Blaxton, 1992). On the basis of the present data and foregoing discussion, we align the type of prospective memory task studied herein (where the intended action is performed in the presence of a target environmental event; see Einstein, McDaniel, Richardson, Guynn, Cunfer, 1995, for discussion of other types of prospective memory tasks) with di- rect associative episodic memory tasks. According to Moscovitch's (1994) systems framework, such tests are mediated in part by a memory module (subserved by hippocampal neuropsychological components) that rapidly and obligatorily delivers to consciousness the information associated with the presented cue. The function of this module is to respond reflexively to cues. The module is engaged when an event (a cue) receives full conscious attention; if the event (the cue) then automatically interacts with a memory trace (e.g., an intended action), then the product of that interaction is delivered to consciousness (Moscovitch, 1994, pp. 276-277). If the event (cue) does not automatically interact with a memory trace (an intended action), then that memory trace is not retrieved unless another memory component (in Mosovitch's formulation, this would be a prefrontal component) initiates a strategic memory search.

The proposal here is that it is this reflexive associative memory system that mediates prospective remembering - that supports retrieval of an intended action when an environmental event that has been previously associated with the intended action is subsequently encountered and processed. This proposal thus provides an account of how remembering occurs when there is no external agent prompting the person to initiate memory retrieval (i.e., when the person is not in a retrieval mode; see Tulving, 1983). Furthermore, the kinds of encodings that are assumed to facilitate the reflexive interaction of a cue with a memory trace (in this associative module) are those that produce more semantic or distinctive information (Moscovitch, 1994). These map directly onto the levels-of-processing encoding manipulation that tended to improve prospective memory (Experiment 3 ) and the picture-format encoding (see Weldon \& Coyote, 1996, for discussion of increased distinctiveness of encoded pictures) that improved prospective memory (Experiment 2). It is also this memory system that is assumed to be responsible for those spontaneous memories that may pop into mind, just as subjects have reported in previous experiments that their prospective remembering was not provided by something they did, rather the memory just popped into mind (Einstein \& McDaniel, 1990).

This account may run into difficulty with one aspect of the data. The associative memory module is assumed to require few cognitive resources such that there should be little interference in its retrieval operations due to concurrent tasks (Moscovitch, 1994). In Experiment 3, there was a clear decline in prospective memory with an additional concurrent task (digit monitoring). One possibility is that the additional concurrent task decreased full conscious attention to encoding the target items (at retrieval), so that the associative memory (hippocampal) system would not have fully apprehended the cue. This possibility is consistent with the finding that the concurrent task did influence pleasantness-rating performance. The concurrent task produced longer rating times for the stimuli, though not different ratings, relative to the nonconcurrent task condition.

Another speculation is that prospective memory performance also requires working memory resources for concurrently holding the ongoing task in mind, keeping the retrieved prospective memory task in mind, sequenc- 
ing these tasks, and interrupting the ongoing tasks (Guynn et al., in press). In the more demanding divided-attention condition (digit monitoring), the controlled resources necessary for working memory (performing pleasantness rating, monitoring and responding to the digit task, holding the retrieved intended action in mind, and interrupting and sequencing those tasks) may be compromised and thereby produce a decrement in the execution of the task. That is, the intention may be automatically retrieved by the hippocampal system, but it may be quickly forgotten in the face of competing demands. Informal observation suggests that this type of prospective memory failure seems to occur in real-world settings. Fuller development of these ideas must await further research, however.

Finally, we note that our results and conclusions might be placed in the broader framework of transfer-appropriate processing. By this view, memory performance will be high to the extent that the information or processing activated at encoding overlaps with the processing induced by the retrieval conditions (see McDaniel, Friedman, \& Bourne, 1978; Morris, Bransford, \& Franks, 1977; Roediger et al., 1989). In our experiments, the retrieval context involved conceptual or semantic processing (i.e., comprehending sentences, Experiments 1 and 2; performing pleasantness ratings for words, Experiment 3). Accordingly, conceptual processing of the prospective memory target event (e.g., at encoding) would be expected to best support (promote better transfer) prospective remembering when the retrieval phase also orients the rememberer toward conceptual processing of stimuli. Of course, most retrieval processes will not be purely conceptual or perceptual, as was evident in Experiment 2 in which the surface-format match at encoding and retrieval had a marginal influence on performance (implying some perceptually driven processes). The main point, however, is it seems possible that if the retrieval phase were heavily weighted toward data-driven processing, then prospective memory would be more influenced by increased perceptual processing of the target item at encoding. Assuming, however, that people's orientation to their focal stimuli is relatively conceptual, it seems that prospective memory in a real-world setting will be primarily conceptually based.

\section{REFERENCES}

ANderson, J. R., \& REDER, L. M. (1979). An elaborative processing explanation of depth of processing. In L. S. Cermak \& F. I. M. Craik (Eds.), Levels of processing in human memory (pp. 385-404). Hillsdale, NJ: Erlbaum.

Battig, W. F., \& Montague, W. E. (1969). Category norms for verbal items in 56 categories: A replication and extension of the Connecticut category norms. Journal of Experimental Psychology Monographs, 80 (No. 3, Pt. 2).

BLAXTON, T. A. (1989). Investigating dissociations among memory measures: Support for a transfer appropriate processing framework. Journal of Experimental Psychology: Learning, Memory, \& Cognition, 15, 657-668.

BLAXTON, T. A. (1992). Dissociations among memory measures in memory-impaired subjects: Evidence for a processing account of memory. Memory \& Cognition, 20, 549-562.
Brandimonte, M., Einstein, G. O., \& McDaniel, M. A. (Eds.) (1996). Prospective memory: Theory and applications. Hillsdale, NJ: Erlbaum.

Brown, A. S., Neblett, D. R., Jones, T. C., \& Mitchell, D. B. (1991). Transfer of processing in repetition priming: Some inappropriate findings. Journal of Experimental Psychology: Learning, Memory, \& Cognition, 17, 514-525.

Challis, B. H., \& BrodBeck, D. R. (1992). Level of processing affects priming in word fragment completion. Journal of Experimental Psychology: Learning, Memory, \& Cognition, 18, 595-607.

Craik, F. I. M., Govoni, R., Naveh-Benjamin, M., \& Anderson, N. D. (1996). The effects of divided attention on encoding and retrieval in human memory. Journal of Experimental Psychology: General, 125, 159-180.

DONALDSON, W. (1992). Measuring recognition memory. Journal of Experimental Psychology: General, 121, 275-277.

EBbinghaus, H. (1964). Memory: A contribution to experimental psychology (H. A. Ruger \& C. E. Bussenius, Trans.). New York: Dover. (Original work published 1885; translated 1913).

EICH, E. (1985). Context, memory, and integrated item/context imagery. Journal of Experimental Psychology: Learning, Memory, \& Cognition, 11, 764-770.

Einstein, G. O., Holland, L. J., McDaniel, M. A., \& Guynn, M. J. (1992). Age related deficits in prospective memory: The influence of task complexity. Psychology \& Aging, 7, 471-478.

Einstein, G. O., \& MCDaniel, M. A. (1990). Normal aging and prospective memory. Journal of Experimental Psychology: Learning. Memory, \& Cognition, 6, 717-726.

Einstein, G. O., \& MCDaniel, M. A. (1996). Retrieval processes in prospective memory: Theoretical approaches and some new empirical findings. In M. Brandimonte, G. O. Einstein, \& M. A. McDaniel (Eds.), Prospective memory: Theory \& applications (pp. 115-142). Hillsdale, NJ: Erlbaum.

Einstein, G. O., MCDaniel, M. A., Richardson, S. L., Guynn, M. J., \& CUNFER, A. R. (1995). Aging and prospective memory: Examining the influences of self-initiated retrieval processes. Journal of Experimental Psychology: Learning, Memory, \& Cognition, 21, 996-1007.

GICK, M. L., CraIK, F. I. M., \& MoRrIs, R. G. (1988). Task complexity and age differences in working memory. Memory \& Cognition, 16, 353-361.

GODDEN, D. R., \& BADDELEY, A. D. (1980). When does context influence recognition memory? British Journal of Psychology, 71, 99-104.

Goldstein, E., Schmitt, J. C., \& Sheirer, C. J. (1978). Semantic effects in encoding specificity: A levels of processing approach. Memory \& Cognition, 6, 13-19.

Guynn, M. J., McDaniel, M. A., \& Einstein, G. O. (in press). Remembering to perform actions: A different type of remembering? In H. D. Zimmer \& R. L. Cohen (Eds.), Memory for action: A distinct form of episodic remembering? New York: Oxford University Press.

HamanN, S. B., \& SQUiRE, L. R. (1996). Level-of-processing effects in word-completion priming: A neuropsychological study. Journal of Experimental Psychology: Learning, Memory, \& Cognition, 22, 933-947.

HUNT, R. R., \& ELLIS, H. C. (1974). Recognition memory and degree of semantic contextual change. Journal of Experimental Psychology, 103, 1153-1159.

JACOBY, L. L. (1983). Remembering the data: Analyzing interactive processes in reading. Journal of Verbal Learning \& Verbal Behavior, 22, 485-508.

JACOBY, L. L. (1984). Incidental versus intentional retrieval: Remembering and awareness as separate issues. In N. Butters \& L. Squire (Eds.), The neuropsychology of memory (pp. 97-122). New York: Guilford. JaCOBY, L. L., Woloshyn, B., \& KeLleY, C. M. (1989). Becoming famous without being recognized: Unconscious influences of memory produced by dividing attention. Journal of Experimental Psychology: General, 118, 115-125.

Light, L. L., \& CARTER-SOBelL, L. (1970). Effects of changed semantic context on recognition memory. Journal of Verbal Learning \& Verbal Behavior, 9, 1-11.

MANDLER, G. (1980). Recognizing: The judgement of previous occurrence. Psychological Review, 87, 252-271. 
Masson, M. E. J., \& Freedman, L. (1990). Fluent identification of repeated words. Journal of Experimental Psychology: Learning, Memory, \& Cognition, 16, 355-373.

Masson, M. E. J., \& MacLeod, C. M. (1992). Re-enacting the route to interpretation: Enhanced perceptual identification without prior perception. Journal of Experimental Psychology: General, 121,145-176.

MatTHEWS, T. D. (1992). Are retrospective and prospective memory related? Unpublished master's thesis, University of North Carolina, Greensboro.

McDaniel, M. A. (1995). Prospective memory: Progress and processes. In D. Medin (Ed.), The psychology of learning and motivation (Vol. 33, pp. 191-221). San Diego, CA: Academic Press.

MCDaniel, M. A., Anderson, D. C., Einstein, G. O., \& O'HalloRAN, C. M. (1989). Modulation of environmental reinstatement effects through encoding strategies. American Journal of Psychology, 102, 523-548.

McDaniel, M. A., \& Einstein, G. O. (1993). The importance of cue familiarity and cue distinctiveness in prospective memory. Memory, 1 , 23-41.

MCDaniel, M. A., Friedman, A. \& Bourne, L. E. (1978). Remembering the levels of information in words. Memory \& Cognition, 6, 156-164.

MCDermott, K. B., \& RoEDiger, H. L., III (1996). Exact and conceptual repetition dissociate conceptual memory tests: Problems for transfer appropriate processing theory. Canadian Journal of Experimental Psychology, 50, 57-71.

Morris, C. D., Bransford, J. P., \& Franks, J. J. (1977). Levels of processing versus transfer appropriate processing. Journal of Verbal Learning \& Verbal Behavior, 16, 519-533.

Moscovirch, M. (1994). Memory and working with memory: Evaluation of a component process model and comparisons with other models. In D. L. Schacter \& E. Tulving (Eds.), Memory systems 1994 (pp. 269-310). Cambridge, MA: MIT Press.

NELSON, D. L. (1979). Remembering pictures and words: Appearance, significance, and name. In L. S. Cermak \& F. I. M. Craik (Eds.), Levels of processing in human memory (pp. 45-76). Hillsdale, NJ: Erlbaum.

PaIvio, A. (1971). Imagery and verbal processes. New York: Oxford University Press.

Paivio, A., \& CSAPC, K. (1973). Picture superiority in free recall: Imagery or dual coding? Cognitive Psychology, 5, 176-206.

RoBINSON, M. B. (1992), Contextual effects in prospective memory. Unpublished master's thesis, Purdue University.

ROBINSON-RIEGLER, M. B. (1994). The recognition-recall hypothesis of prospective memory. Unpublished doctoral dissertation, Purdue University.

Roediger, H. L., III, \& Blaxton, T. A. (1987). Retrieval modes produce dissociations in memory for surface information. In D. Gorfein \& R. R. Hoffman (Eds.), Memory and cognitive processes: The Ebbinghaus Centennial Conference (pp. 349-379). Hillsdale, NJ: Erlbaum.

Roediger, H. L., III, Weldon, M. S., \& Challis, B. H. (1989). Explaining dissociations between implicit and explicit measures of retention: A processing account. In H. L. Roediger III \& F. I. M. Craik (Eds.), Varieties of memory and consciousness: Essays in honour of Endel Tulving (pp. 3-41). Hillsdale, NJ: Erlbaum.

Roediger, H. L., III, Weldon, M. S., Stadler, M. L., \& Riegler, G. L. (1992). Direct comparison of two implicit memory tests: Word fragment and word stem completion. Journal of Experimental Psychology: Learning, Memory, \& Cognition, 18, 1251-1269.

SHEPARD, R. N. (1967). Recognition memory for words, sentences, and pictures. Journal of Verbal Learning \& Verbal Behavior, 6, 156-163.

SMITH, M. C., \& MAGEE, L. E. (1980). Tracing the time course of picture- word processing. Journal of Experimental Psychology: General, 109, 373-392.

SMITH, S. M. (1988). Environmental context-dependent memory. In G. M. Davies \& D. M. Thomson (Eds.), Memory in context: Context in memory (pp. 13-33). New York: Wiley.

Smith, S. M., Glenrerg, A., \& BJork, R. A. (1978). Environmental context and human memory. Memory \& Cognition, 6, 342-353.

Toglia, M. P., \& BatTiG, W. F. (1978). Handbook of semantic word norms. Hillsdale, NJ: Erlbaum.

Tulving, E. (1983). Elements of episodic memory. New York: Oxford University Press.

WELDON, M. S. (1991). Mechanisms underlying priming on perceptual tests. Journal of Experimental Psychology: Learning, Memory, \& Cognition, 17, 526-541

WELDON, M. S., \& COYOTE, K. C. (1996). Failure to find the picture superiority effect in implicit conceptual memory tests. Journal of Experimental Psychology: Learning, Memory, \& Cognition, 22, 670-686.

WELDON, M. S., \& Roediger, H. L., III (1987). Altering retrieval demands reverses the picture superiority effect. Memory \& Cognition, 15, 269-280.

Weldon, M. S., Roediger, H. L., III, \& Challis, B. H. (1989). The properties of retrieval cues constrain the picture superiority effect. Memory \& Cognition, 17, 95-105.

\section{NOTES}

1. Due to computer error, data for some sentences were omitted for some subjects. Hence, the measure analyzed was proportion correct for each participant.

2 . The computer files for the pleasantness-rating data for 6 subjects in each condition were misplaced when the first and second authors moved from Purdue University.

3. We thank an anonymous reviewer for raising this issue.

\section{APPENDIX A \\ Sentences for the Prospective Memory Target Encoding in Experiment 1}

bat (stick)

Equipment used in a baseball game includes a bat and a glove. A frightened home owner might use a baseball bat for protection.

bat (animal)

A bat is active at night and sleeps during the day.

A dark attic is one possible place to see a bat flying.

chest (trunk)

A cedar chest can be kept in a basement or a bedroom.

A treasure chest could be dug up on a desert island.

chest (anatomy)

One sign of puberty is that boys start to grow chest hair.

The most important muscle in the chest is known as the heart. pool (swimming)

Excessive amounts of chlorine in a pool can irritate your eyes.

A summer day may be spent swimming at the pool or lake. pool (tabletop game)

A pool table might be bought to furnish a recreation room. 
APPENDIX B

Example Sentences (Using bat [stick] as Encoding Target) for the Prospective Memory Test in Experiment 1

\begin{tabular}{|c|c|c|}
\hline Same & Modulated & Different \\
\hline $\begin{array}{l}\text { A hard swing of the } \\
\text { bat could lead to a } \\
\text { home run. }\end{array}$ & $\begin{array}{l}\text { Kids in a gang might } \\
\text { use a bat. }\end{array}$ & $\begin{array}{l}\text { A bat travels from } \\
\text { place to place by } \\
\text { flying through the air. }\end{array}$ \\
\hline $\begin{array}{l}\text { During a baseball } \\
\text { game, a bat and ball } \\
\text { never make contact. }\end{array}$ & $\begin{array}{l}\text { A bat would be } \\
\text { totally useless in an } \\
\text { attempt at self-defense. }\end{array}$ & $\begin{array}{l}\text { A bat is commonly } \\
\text { classified as a } \\
\text { bird because it flies. }\end{array}$ \\
\hline $\begin{array}{l}\text { A baseball player } \\
\text { will use a bat several } \\
\text { times in a game. }\end{array}$ & $\begin{array}{l}\text { Although unconventional, } \\
\text { a bat could serve as } \\
\text { a weapon. }\end{array}$ & $\begin{array}{l}\text { The webbed wings } \\
\text { of a bat allow it to fly. }\end{array}$ \\
\hline $\begin{array}{l}\text { A bat is commonly } \\
\text { used by a player } \\
\text { to catch a baseball. }\end{array}$ & $\begin{array}{l}\text { Physically harming a } \\
\text { person with a bat would } \\
\text { be unconventional. }\end{array}$ & $\begin{array}{l}\text { Flight is impossible } \\
\text { for a bat even though } \\
\text { it has wings. }\end{array}$ \\
\hline
\end{tabular}

(Manuscript received July 3, 1996;

revision accepted for publication December 9, 1996.) 